\title{
ALGUNS ASPECTOS CLIMATICOS DO MUNICÍPIO DE JABOTICABAL - SP
}

\author{
ANDRE, Romisio Geraldo Bouhid ${ }^{1}$
}

GARCIA, Anice ${ }^{2}$

\begin{abstract}
RESUMO: O estudo teve como objetivo analisar as características climáticas do Município de Jaboticabal SP.Foram utilizados dados mensais de temperatura média do ar e de precipitação pluviométrica para um período de 43 anos (1971 a 2013). Os dados foram coletados na Estação Agroclimatológica da Universidade Estadual Paulista Campus de Jaboticabal( Lat. 21 14'45”S; Long: 481858 O; Alt: 595 m). Foram determinados os índices de aridez (Ia) e de umidade (Im), os tipos de clima segundo Köppen-Geiger e Thornthwaite, bem como os balanços hídricos, para períodos selecionados.Os resultados obtidos mostraram uma tendência de acréscimo de Ia, bem como, um decréscimo de Im. A Classificação de Köppen-Geiger resultou em clima Aw - Tropical de savana, com seca no inverno. Já a classificação de Thornthwaite, mostra resultados de clima úmido com pequena deficiência no inverno, clima mesotérmico, ou seja, com grande amplitude térmica anual. Finalmente o balanço hídrico resultou em um decréscimo do excesso anual de água e, um acréscimo do déficit anual de água no solo.
\end{abstract}

Palavras-chave: Índices de umidade. Clima. Déficit de água.

SUMMARY: The study aimed to analise the climatic characteristic of Jaboticabal /SP. The analysis of the parameters was made monthly, seasonal, annual and interannual. Data (1971-2013) were collected in Agrometeorological Station of $\mathrm{t}$ : he Universidade Estadual Paulista (UNESP) at Jaboticabal Campus(Lat; $21^{\circ} 14^{\prime} 05^{\prime}$ 'S; Long: 48 $17^{\circ} 09^{\prime \prime} \mathrm{W}$; Alt: 616.01m). Dry and wet índex, climatic types, by Koppen-Geiger and Thornthwaite aproachs as well the water balance for several períods were obtained. The results shown in a increase Ia and a decrease Im trends with the years. The Koppen-Geiger classfication shows a climatic type Aw- tropical savana along dry winters. Thornthwaite's classification shows wet climat, mesotermic. Finnaly the water balance presents a decrease of the anual excess of water and a increase of anual déficit of water in soil.

Keywords: Umidity index. Climate. Water deficit.

\section{INTRODUÇÃO}

Dados climáticos são essenciais no planejamento e redução de riscos associados a anomalias do clima. Avaliação e previsão dos impactos da variabilidade climática de curto prazo e os riscos climáticos, bem como sua relação com eventos extremos, poderiam ajudar a atenuar os efeitos da variabilidade climática e facilitar a programação das atividades agrícolas (GARCIA et al., 2010).

Para compreensão dos processos climatológicos de uma região torna-se necessário um prévio conhecimento de seus diversos fatores, alguns de ordem estática, outros de natureza dinâmica, todos atuando simultaneamente. No caso da Região sudeste do Brasil podem-se citar a posição latitudinal e a proximidade do Oceano Atlântico como fatores estáticos do clima. Outro fator estático de suma importância é a topografia acidentada (NIMER, 1989). Por estas razões, a variabilidade das precipitações é elevada nestas regiões.

Segundo a classificação climática de Köppen-Geiger, baseada em dados mensais pluviométricos e termométricos, o Estado de São Paulo abrange sete tipos climáticos distintos, a maioria correspondente a clima úmido (Fig.1). O tipo dominante na maior área é o Cwa , que abrange toda a parte central do Estado e é caracterizado pelo clima tropical de altitude, com chuvas no verão e inverno seco, com a temperatura

\footnotetext{
${ }^{1}$ Departamento de C. Exatas- FCAV/UNESP - Jaboticabal -SP (aposentado)

${ }^{2}$ Fundação Educacional de Ituverava. Faculdade Dr. Francisco Maeda.
} 
média do mês mais quente superior a $22^{\circ} \mathrm{C}$. Algumas áreas serranas, com o verão ameno são classificadas no tipo $\mathrm{Cwb}$, onde a temperatura média do mês mais quente é inferior a $22^{\circ} \mathrm{C}$ e durante pelo menos quatro meses é superior a $10{ }^{\circ} \mathrm{C}$.

As regiões a Noroeste, mais quentes, pertencem ao tipo Aw, tropical chuvoso com inverno seco e mês mais frio com temperatura média superior a $18^{\circ} \mathrm{C}$. O mês mais seco tem precipitação inferior a $60 \mathrm{~mm}$ e com período chuvoso que se atrasa para o outono. Em pontos isolados ocorre o tipo Am que caracteriza o clima tropical chuvoso, com inverno seco onde o mês menos chuvoso tem precipitação inferior a $60 \mathrm{~mm}$. $\mathrm{O}$ mês mais frio tem temperatura média superior a $18^{\circ} \mathrm{C}$.

No Sul do Estado aparecem faixas de clima tropical, com verão quente, sem estação seca de inverno, do tipo Cfa onde a temperatura média do mês mais frio está entre $18^{\circ} \mathrm{C} \mathrm{e}-3^{\circ} \mathrm{C}$, tipo mesotérmico. As áreas serranas, mais altas, das serras do Mar e da Mantiqueira, com verão ameno e chuvoso o ano todo têm o clima classificado como $\mathrm{Cfb}$ de verão um pouco mais ameno, onde o mês mais quente tem temperatura média inferior a $22^{\circ} \mathrm{C}$.

A faixa litorânea recebe a classificação Af, caracterizada pelo clima tropical chuvoso, sem estação seca com a precipitação média do mês mais seco superior a $60 \mathrm{~mm}$.

Fig.1. Classificação Climática do Estado de São Paulo (Fonte: EPAGRI - UNICAMP)

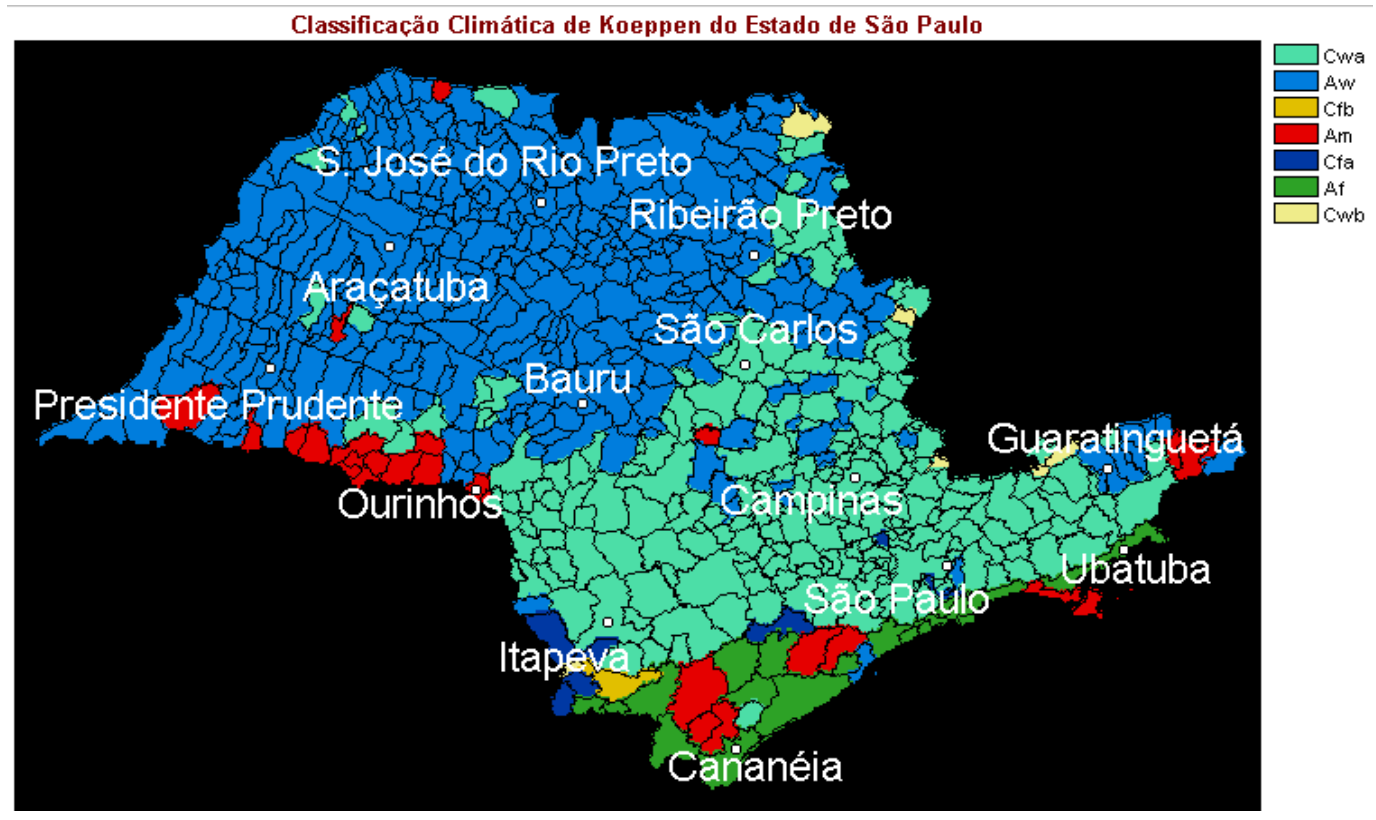

Para elaboração de uma classificação climática a primeira providência é se dispor uma base de dados confiáveis e consistidos de precipitação e temperatura, de um período de 30 anos (O.M.M., 1975).

Andre et al. (2004) com o objetivo de analisar o comportamento climatológico da precipitação, em 14 localidades da Região Norte Fluminense, utilizando-se dos índices de aridez, umidade e anomalia da precipitação e uma série de 30 anos de dados (1971 a 2000) observaram que das 14 localidades, cinco apresentaram uma tendência de crescimento gradual do índice de aridez além de diminuição do índice de umidade e da anomalia da precipitação.

Garcia et al (2006) estudaram a variabilidade das chuvas em Ituverava - SP, nos períodos de 1991 a 2001 e analisaram o balanço hídrico para o mesmo período. Concluíram que o município não apresenta grandes limitações hídricas para a maioria das culturas, entretanto, durante o inverno, e dependendo da 
cultura a ser implantada, a irrigação é uma prática recomendável. Conclusões semelhantes foram obtidas por:

André e Garcia (2014) analisando dados de precipitação de 1956 a 2013, para a localidade de Jaboticabal - SP. Mendonça et al (2009) avaliaram a variação temporal dos índices de umidade e de aridez para diferentes municípios das regiões Norte e Noroeste Fluminense a partir de uma série de 70 anos de dados pluviométricos médios mensais, procurando classificá-los dentro das regiões homogêneas em precipitação, previamente determinadas.

Garcia e André (2015) analisaram dados de temperaturas (máxima, mínima e média), no período 1971-2013, para a localidade de Jaboticabal - SP e concluíram que as temperaturas calculadas pelo método de extremas (médias entre máximas e mínimas) e corrigidas pelas equações obtidas no referido trabalho, aproximam-se muito da temperatura obtida pelo padrão do INMET.

Este trabalho teve como objetivo estudar as características climáticas do Município de Jaboticabal - SP, através das determinações dos índices da aridez e umidade, das classificações climáticas de Koeppen- Geiger e Thornthwaite, bem como da análise dos balanços hídricos para períodos específicos.

\section{MATERIAL E MÉTODO}

Para o cálculo do balanço hídrico foi utilizado o método de THORNTHWAITE \& MATHER (1955). Adotou-se a capacidade de água disponível (CAD) de $125 \mathrm{~mm}$, correspondente ao conteúdo de água armazenada no solo para uma profundidade efetiva das raízes de $100 \mathrm{~cm}$. Os cálculos dos balanços hídricos para Jaboticabal - SP foram realizados utilizando-se o Software desenvolvido por SENTELHAS et al. (1999).

Com os resultados do balanço hídrico sequencial, feitos ano a ano foram determinados os índices de umidade e de aridez (Vianello \& Alves, 2013), a saber:

$$
\mathrm{Im}=\mathrm{EXC} / \mathrm{ETP}-0,6 \mathrm{Ia}
$$

O Índice de aridez (Ia) é dado por:

$$
\mathrm{Ia}=\mathrm{DEF} / \mathrm{ETP}
$$

Os limites para o índice de umidade são os seguintes:

$$
\begin{aligned}
20 & <\operatorname{Im}<40-\text { úmido } \\
0 & <\mathrm{Im}<20-\text { sub-úmido } \\
-20 & <\mathrm{Im}<0-\text { sub-úmido seco } \\
-40 & <\mathrm{Im}<-20 \text { - semi-árido }
\end{aligned}
$$

Para o índice de aridez os limites são:

$0<$ Ia $<16,7$ - deficiência d'água pequena ou nula

16,7 < Ia < 33,3 - deficiência d'água moderada no inverno

Ia > 33,3 - grande deficiência d'água no inverno 


\section{RESULTADOS E DISCUSSÃO}

A Figura 2 mostra os resultados obtidos para os índices de aridez e de umidade para Jaboticabal SP, durante o período estudado (1971-2013).

A análise da Figura 2 mostra que o Índice de aridez (Ia) cresce gradativamente de 1971 a 2013 mostrando valores entre 0 e +20 na maior parte dos anos, o que mostra que a região apresenta deficiência de água moderada nos meses de inverno. Com relação ao Índice de umidade (Im) vê-se que o mesmo é decrescente com o decorrer dos anos, com valores permanecendo entre +20 e +40 que mostra que a região em estudo possui clima úmido e, em alguns anos, sub-úmido.

Isto pode estar relacionado a mudanças ocorridas na cobertura vegetal com o decorrer dos anos estudados.

Fig.2. Variação anual dos índices de aridez e de umidade, para Jaboticabal, SP, durante o período considerado.

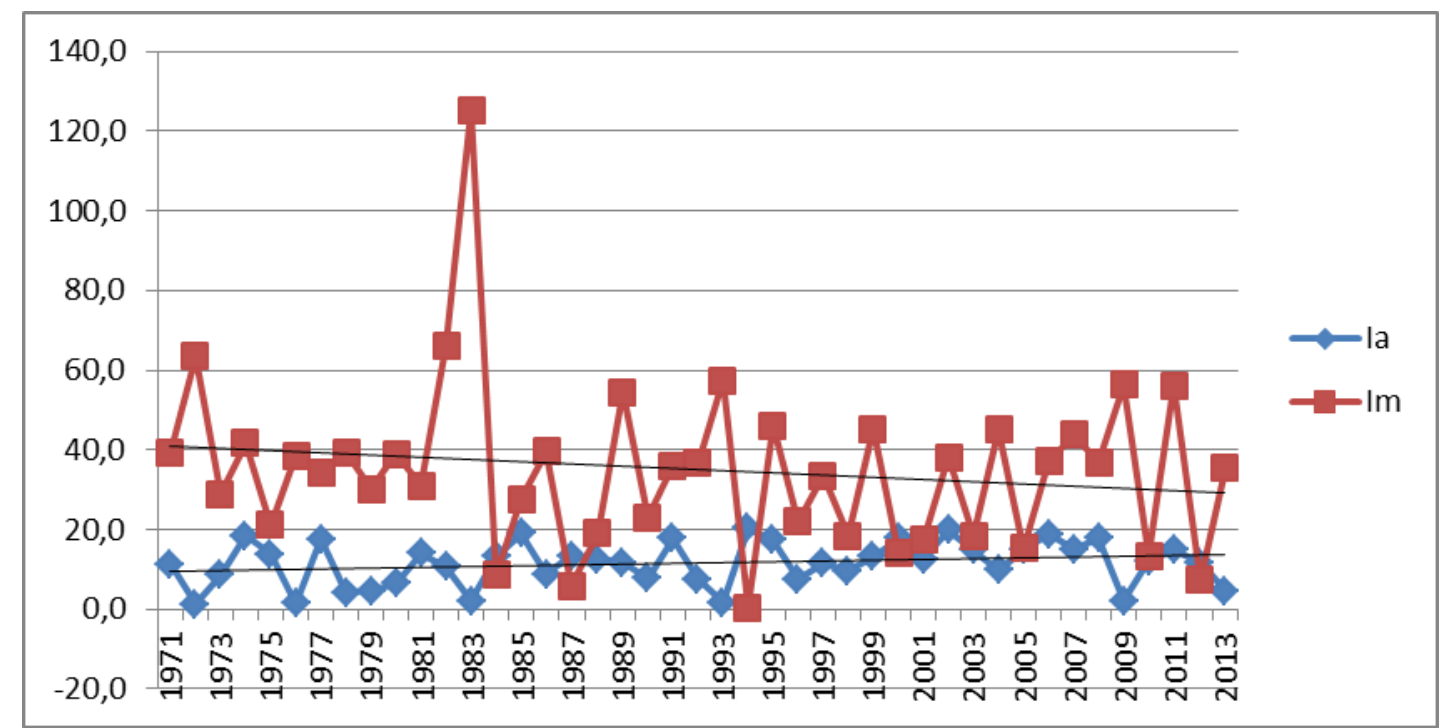

Com base nos dados médios de temperatura e precipitação e, nos balanços hídricos realizados para os períodos 1971-1980; 1981-1990; 1991-2000; 2001- 2013 e 1971-2013, foi feita a classificação do Clima Local segundo Köppen-Geiger e Thornthwaite, para Jaboticabal, SP, nesses períodos. Os resultados estão mostrados na Tabela 1.

Tabela 1. Classificação Climática para Jaboticabal, SP,para os períodos: 1971-1980; 1981-1990; 1991-2000; 2001-2013 e 1971-2013 ( normal climatológica).

\begin{tabular}{cccccccc}
\hline ANO & ETP & DEF & EXC & Ia & Im & Thornth. & Koppen \\
\hline $1971-1980$ & 1126,7 & 73,6 & 349,9 & 6,532 & 27,136 & B1rB'4 $^{\prime}$ & Aw \\
$1981-1990$ & 1155,6 & 96,8 & 424,2 & 8,377 & 31,682 & B1rA $^{\prime}$ & Aw \\
$1991-2000$ & 1167,0 & 120,4 & 341,7 & 10,317 & 23,090 & $"$ & Aw \\
$2001-2013$ & 1184,2 & 132,5 & 371,7 & 11,189 & 24,675 & $"$ & Aw \\
$1971-2013$ & 1116,0 & 101,3 & 365,6 & 9,077 & 27,314 & B1rB' 4 & Aw \\
\hline
\end{tabular}

ETP: evapotranspiração potencial, DEF: deficiência hídrica; EXC: excedente hídrico; Ia: Índice de aridez; Im: índice de umidade. Thornth: classificação de Thornthwaite e Koppen: classificação de Köppen-Geiger. 
Nota-se que a Classificação de Köppen-Geiser mostra resultados dentro do esperado para a região, com clima Aw - Tropical de savana, com seca no inverno. O cerrado brasileiro, é considerado uma área de savana, cuja vegetação predominante são as gramíneas, com árvores esparsas e arbustos isolados ou em pequenos grupos. É o bioma típico de regiões de clima tropical com estação seca. Já a classificação de Thornthwaite, mostra resultados de clima úmido com pequena deficiência no inverno, clima mesotérmico, ou seja, com grande amplitude térmica anual. É bom notar que a classificação climática de KöppenGeiger, funciona com maior eficiência para macroescala,com baixa capacidade para separação dos tipos de clima, levando-se em conta a temperatura do ar e precipitação. Por outro lado, o sistema de Thornthwaite permite separar mais eficientemente os climas regionais demonstrando, dessa forma, maior capacidade para determinação de zonas agroclimáticas (Rolim, et al., 2007).

Os extratos do balanço hídrico, segundo Thornthwaite, realizado para os períodos citados, estão representados nas Figuras 3 (a) a 3 (e).

Fig. 3. Deficiência, excedente, retirada e reposição extraídos do balanço hídrico para Jaboticabal, SP, nos períodos de 1971-1980; 1981-1990; 1991-2000; 2001-2013 e 1971-2013 ( normal climatológica)..
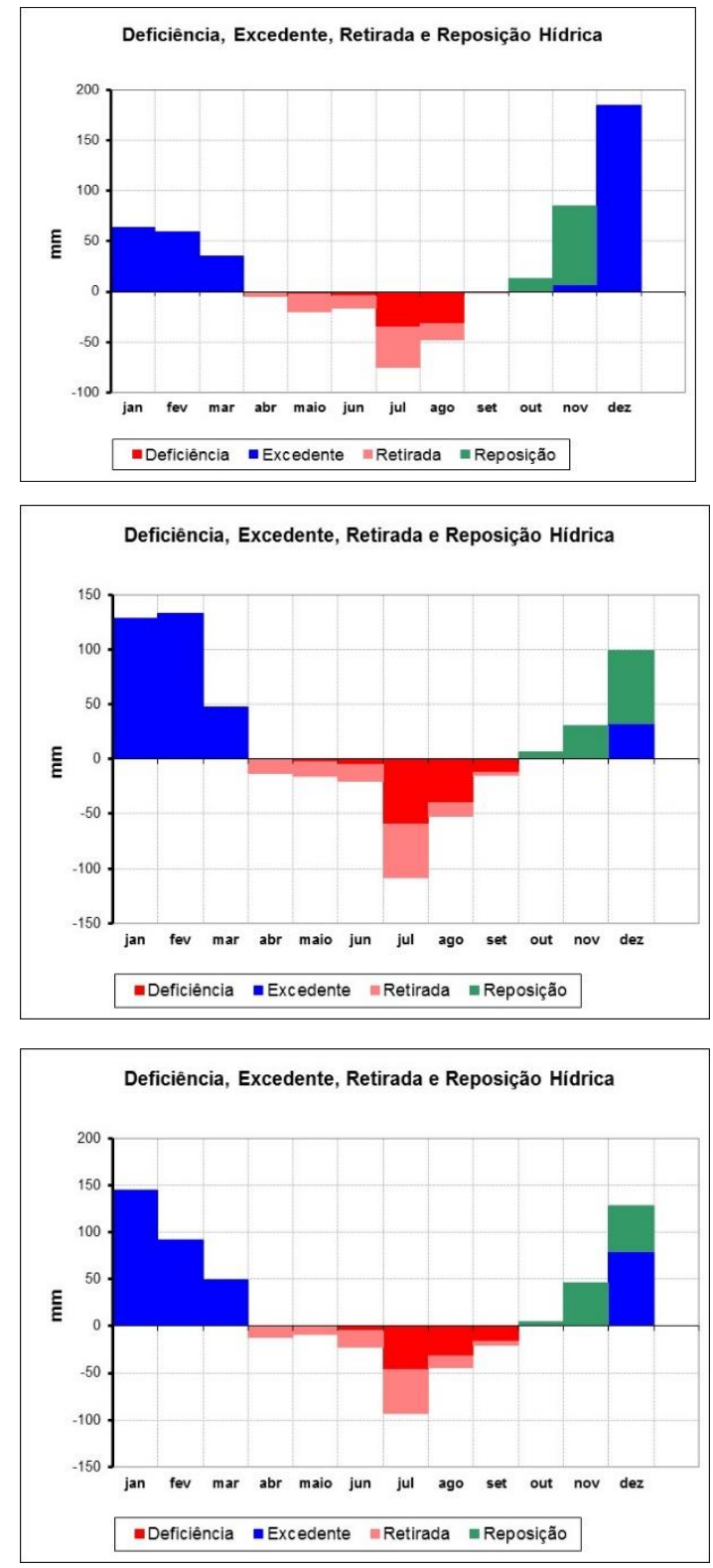
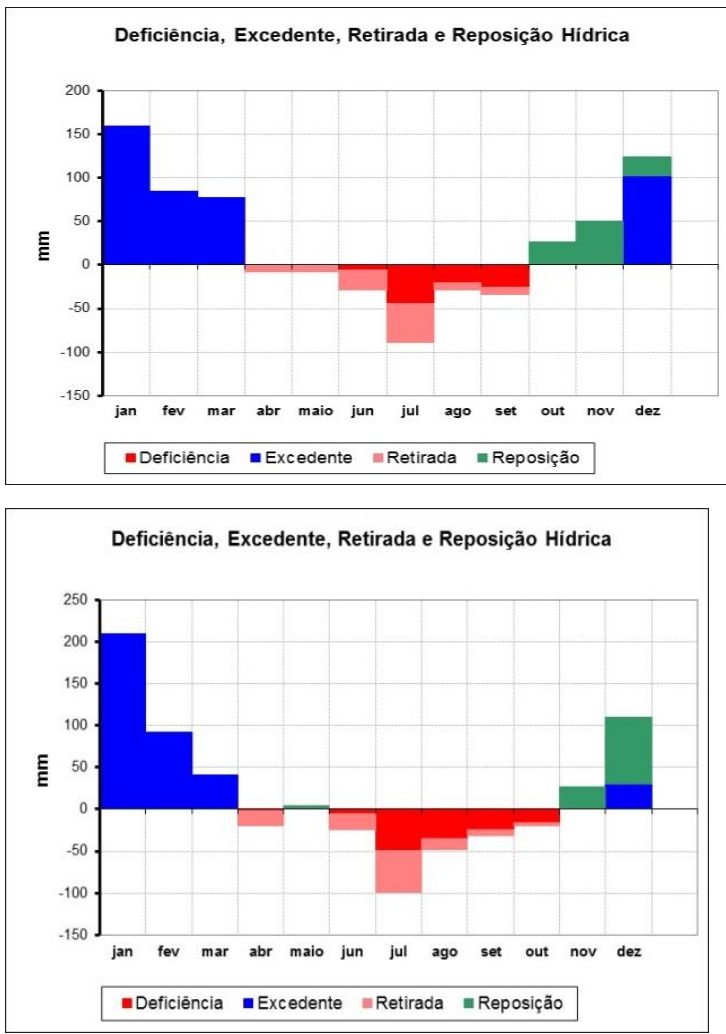
Essas figuras mostram que o déficit de umidade cresceu com o decorrer dos anos, nos períodos estudados em cerca de $80 \%$ (de 73,6 a 132,5 mm), sendo o valor normal de 101,3 mm. Embora a precipitação tenha se apresentado com uma ligeira tendência de aumento, como observado por ANDRÉ e GARCIA (2014). O aumento do déficit pode ser explicado pelo aumento da temperatura durante o mesmo período, sendo que a média anual da temperatura nos períodos estudados foi de $21,9^{\circ} \mathrm{C}$ para o período de $1971-1980,22,3^{\circ} \mathrm{C}$ para o período de $1981-1990,22,3^{\circ} \mathrm{C}$ para o período de $1991-2000$ e $22,5^{\circ} \mathrm{C}$ para o período de 2001-2013.

A Figura 4 mostra o desempenho anual do déficit e do excesso para Jaboticabal, SP. A linha de tendência ajustada aos dados, mostra um decréscimo do excesso anual de água e, um acréscimo do déficit de água na região estudada.

Figura 4. Déficit e excesso anual de umidade ( $\mathrm{mm})$, para Jaboticabal, SP, durante o período estudado.

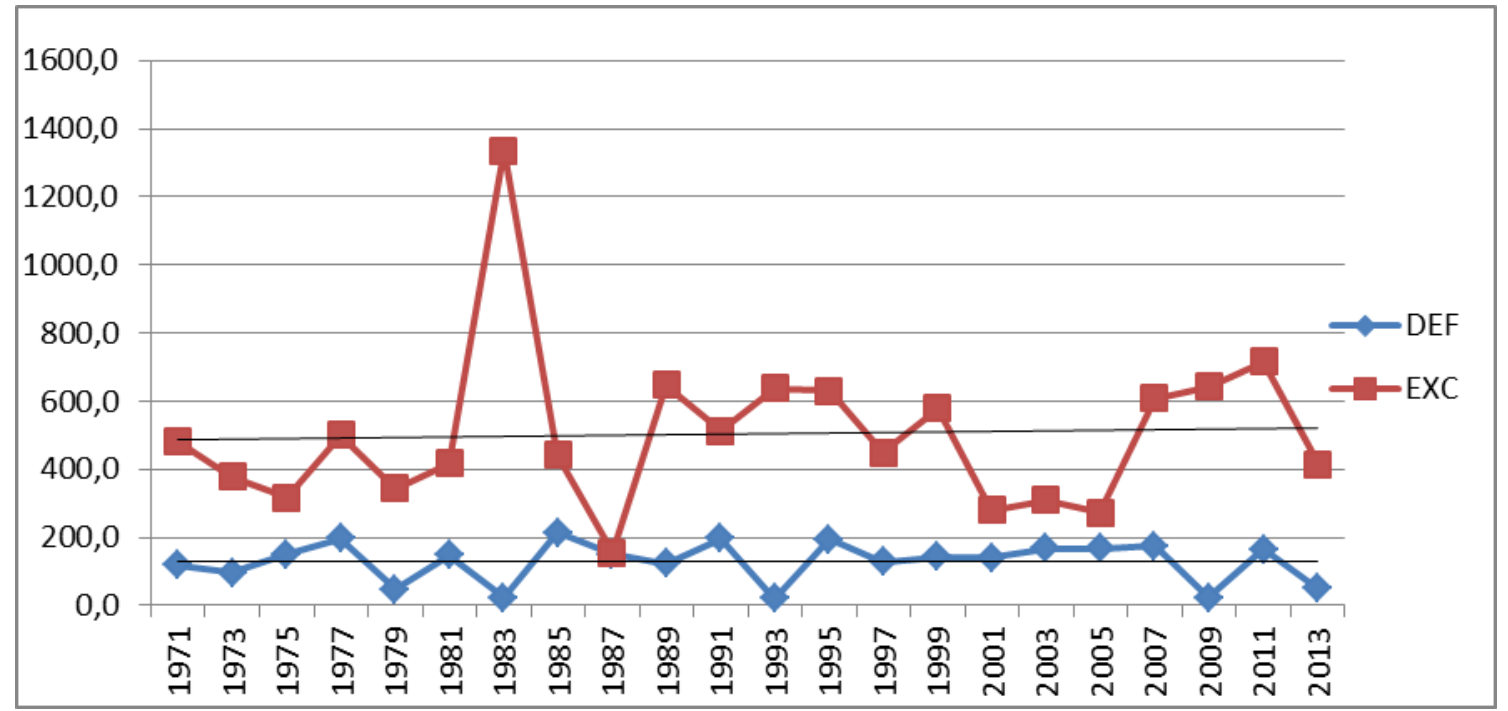

Mais uma vez, acredita-se que esta tendência de aumento do déficit anual de umidade e decréscimo do excesso anual de umidade, deve-se ao fato de mudanças na cobertura vegetal e das práticas agrícolas durante os anos estudados, que influenciaram nos valores de temperatura.

\section{CONCLUSÃO}

Os autores observaram um crescimento do índice de aridez e uma diminuição do índice de umidade com o decorrer dos anos. O clima da micro-região, pelo sistema de Köppen-Geiger, foi o Awtropical de savana, com inverno seco e, pelo sistema de Thornthwaite, mostra a região com clima úmido com pequena deficiência no inverno. Os resultados mostraram também, que o déficit hídrico vem aumentando com o decorrer dos anos, mesmo com o aumento das precipitações.

\section{REFERÊNCIAS}

ANDRÉ, R. G. B. ; PINHEIRO, F. M. A. ; MARQUES, V. S. Índice de aridez e de umidade para a região Norte Fluminense. In: Anais do XIII CBMET - Congresso Brasileiro de Meteorologia, Fortaleza, CE, 2004. 
ANDRÉ, R.G.B., GARCIA, A. Variabilidade temporal da precipitação em Jaboticabal, SP. Nucleus, v.11, n2, p.397- 402, 2014.

CEPAGRI - UNICAMP. A Classificação Climática de Koeppen para o Estado de São Paulo. CEPAGRI UNICAMP. Disponível em (www.cpa.unicamp.br).

GARCIA, A.et al. 2010. Climate and weather risk assessment for agricultural planning. Guide to Agricultural Meteorological Practices (GAMP) Draft 3rd Edition (WMO-No. 134) Chapter 7. Available at http://www.wmo.int/pages/prog/wcp/agm/gamp/documents/WMO_No134_en.pdf. Acessado em $\underline{02 / 07 / 2015 .}$

GARCIA, A., ANDRÉ, R.G.B. Variabilidade temporal da temperatura do ar em Jaboticabal - SP, Nucleus, v.12 n.1, p.181-188, 2015.

GARCIA, A.; ANDRÉ, R. G. B.; CARRER, T. T. Precipitation analysis (temporal variation and anomalies) in Ituverava-São Paulo State-Brazil. The International Journal of Meteorology, v. 31, p. 155$163,2006$.

MENDONÇA, J.C.et al. Avaliação de índices climáticos nas regiões Norte e Noroeste do Estado do Rio de Janeiro. In: III Simposio Internacional de Climatologia, 2009. Canela -RS.

NIMER, E. Climatologia do Brasil. $2^{\mathrm{a}}$ ed. Rio de Janeiro : IBGE, Departamento de Recursos Naturais e Estudos Ambientais, 422p., 1989.

ROLIM, G.S.et al. Classificação climática de Koeppen na determinação de zonas agroclimáticas para o estado de São Paulo. Bragantia, Campinas, v. 66, n 4, p.711-720, 2007.

SENTELHAS, P.C. et al. Balanços hídricos climatológicos do Brasil. ESALQ/USP- Piracicaba - SP, 1999. CD-ROM.

THORnTHWAite, C.W., MATHER, J.R. The water balance. Publications in Climatology. New Jersey, Drexel Institute of Technology, 104p., 1955.

VIANELLO, R.L.; ALVES, A.R. Meteorologia Básica e aplicações. $2^{a}$ Ed., Editora da Universidade Federal de Viçosa, 460, 2012.

WORLD METEOROLOGICAL ORGANIZATION: Drought and agriculture. WMO Tech. Note 138, Publ. WMO-392, Geneva, Switzerland, 127p. 1975 
